\title{
Somatic NLRP3 mosaicism in Muckle-Wells syndrome
}

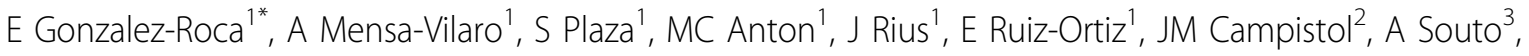 \\ J Cañellas ${ }^{4}$, K Nakagawa $^{5}$, R Nishikomori ${ }^{5}$, J Yagüe ${ }^{1}$, Jl Arostegui $^{1}$ \\ From 8th International Congress of Familial Mediterranean Fever and Systemic Autoinflammatory Diseases \\ Dresden, Germany. 30 September - 3 October 2015
}

\section{Introduction}

Familial cold autoinflammatory syndrome, Muckle-Wells syndrome (MWS), and chronic, infantile, neurological, cutaneous and articular (CINCA) syndrome are dominantly inherited autoinflammatory diseases associated to gain-of-function NLRP3 mutations. All these diseases are currently considered as different phenotypes of the cryopyrin-associated periodic syndromes (CAPS). A variable degree of somatic NLRP3 mosaicism has been recently detected in $\approx 35 \%$ of patients with CINCA. However, no data are currently available regarding the relevance of this genetic mechanism in other CAPS phenotypes.

\section{Objective}

To evaluate somatic NLRP3 mosaicism as the diseasecausing mechanism in patients with CAPS phenotypes other than CINCA and NLRP3 mutation-negative by conventional, Sanger-based genetic studies.

\section{Materials and methods}

NLRP3 analyses were performed by Sanger sequencing and by targeted deep sequencing. Apoptosis-associated Speck-like protein containing a CARD (ASC)-dependent nuclear factor kappa-light chain enhancer of activated $\mathrm{B}$ cells $(\mathrm{NF}-\kappa \mathrm{B})$ activation and transfection-induced THP-1 cell death assays determined the functional consequences of the detected variants.

\section{Results}

32 Spanish patients fulfilling clinical inclusion criteria were enrolled. A variable degree (9.4-34.9\%) of somatic NLRP3 mosaicism was detected in $9.3 \%$ of enrolled

${ }^{1}$ Hospital Clinic, Immunology, Barcelona, Spain

Full list of author information is available at the end of the article patients (3/32). Their clinical phenotypes were identical to that seen in MWS. Three different missense variants (p.D303A, p.L411F and p.F523L) were identified, being two novels (p.D303A and p.L411F). Bioinformatic and functional analyses confirmed that they were diseasecausing, gain-of-function NLRP3 mutations. Treatment with anti-IL-1 drugs showed long-lasting and positive clinical and biochemical responses.

\section{Conclusion}

We herein show novel evidence about the role of somatic NLRP3 mosaicism in MWS pathogenesis, which probably represents a shared genetic mechanism in CAPS not restricted to CINCA syndrome. The data here described allowed us to achieve the definitive diagnoses of these patients, which have had serious clinical implications such as gaining access to anti-IL-1 treatments under legal indication and genetic counseling. The detection of somatic gene mosaicism is difficult when using conventional methods. Potential candidates should benefit from the use of novel technologies such as targeted deep sequencing.

\section{Authors' details \\ ${ }^{1}$ Hospital Clinic, Immunology, Barcelona, Spain. ${ }^{2}$ Hospital Clinic, Nephrology, Barcelona, Spain. ${ }^{3}$ Hospital Universitario Santiago de Compostela, Rheumatology, Santiago de Compostela, Spain. ${ }^{4}$ Hospital Universitari Germans Trias i Pujol, Rheumatology, Badalona, Spain. ${ }^{5}$ Kyoto University, Pediatrics, Kyoto, Japan.}

Published: 28 September 2015

doi:10.1186/1546-0096-13-S1-P61

Cite this article as: Gonzalez-Roca et al: Somatic NLRP3 mosaicism in Muckle-Wells syndrome. Pediatric Rheumatology 2015 13(Suppl 1):P61.
Ciomed Central

(c) 2015 Gonzalez-Roca et al. This is an Open Access article distributed under the terms of the Creative Commons Attribution License (http://creativecommons.org/licenses/by/4.0), which permits unrestricted use, distribution, and reproduction in any medium, provided the original work is properly cited. The Creative Commons Public Domain Dedication waiver (http://creativecommons.org/ publicdomain/zero/1.0/) applies to the data made available in this article, unless otherwise stated. 